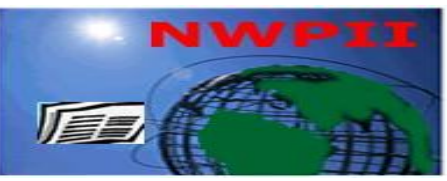

American Journal of Biomedical Sciences

ISSN: 1937-9080

nwpii.com/ajbms

\title{
Pathophysiological Assessment of Bisephenol A and Di (2-ethylhexyl)Phthalate on Hepatic and Renal Function Parameters of Albino Wistar Rats
}

\author{
Nosa Terry Omorodion ${ }^{1}$, Peter Uwadiegwu Achukwu ${ }^{2}$, Alphonsus Ogbonna Ogbuabor ${ }^{3}$ \\ ${ }^{1}$ Health Services Department, University Of Benin, Ugbowo, Benin City, Nigeria \\ ${ }^{2}$ Department Of Medical Laboratory Sciences, University Of Nigeria, Enugu Campus, Enugu, Nigeria \\ ${ }^{3}$ Department Of Medical Laboratory Sciences, Enugu State University Teaching, Parklane, Enugu State, Nigeria \\ "Corresponding Author \\ Nosa Terry Omorodion \\ Health Services Department, University Of Benin, \\ Ugbowo, Benin City, \\ Nigeria \\ Email: terry.omorodion@uniben.edu \\ Phone:+2348136742270
}

Received:06 December 2018 ; | Revised:26 December 2018; | Accepted:14 March 2019

\begin{abstract}
The ubiquitous nature of plastics has raised concerns pertaining to continuous exposure to plastic polymers and human health risks of particular concern are the use of endocrine-disrupting chemicals (EDCs) in plastic production, including Di(2-ethylhexyl) phthalate (DEHP) and Bisphenol A (BPA). The aim of this work is to evaluate the pathological effect of bisephenol a and di(2-etylhexyl)phthalate on weight, liver and liver function parameters of albino wistar rats. An experimental study involving 60 Wistar rats was carried out. The rats were divided into four groups of $15 \mathrm{Wistar}$ rat each in a group. The group I received normal rats pellet and water and served as control group, group II received $5 \mathrm{mg} / \mathrm{kg} / \mathrm{day}$ of BPA mixed with rat pellet orally, group III received $0.5 \mathrm{mg} / \mathrm{kg}$ daily of DEHP mixed with rat pellet while group IV received orally mixture of $0.5 \mathrm{mg} / \mathrm{kg} \mathrm{BPA}$ and $0.5 \mathrm{mg} / \mathrm{kg}$ DEHP + rat pellet. The rats were fed for 30 consecutive days after which they were sacrificed and an analysis was carried out on them. The laboratory analysis revealed significant variations in the concentration of liver function test, kidney function test and weight size in group II, III, and IV comparison with group I (control). In conclusion, the present work reveals that Bpa and Dehp alters the proper functioning of the hepatic and renal functioning and can also lead to severe weight loss.
\end{abstract}

Keywords: Liver, Kidney, Bisephenol A, Di (2-ethylhexyl)phathalate

\section{Introduction}

The ubiquitous nature of plastics has raised concerns pertaining to continuous exposure to plastic polymers and human health risks of particular concern is the use of endocrine-disrupting 
chemicals (EDCs) in plastic production, including Di(2-ethylhexyl) phthalate (DEHP) and Bisphenol A (BPA).

Epidemiological studies have offered evidence for the possible relationship between exposure to phthalates and PVC materials and the risk of asthma and allergy both in workers of plastic industry and in children ${ }^{[1-6]}$

Studies on the impact of BPA on adipose tissue yielded conflicting and hard to interpret data, most likely due to the wide range of administered doses. BPA accumulation in rat adipose tissue was low in one study ${ }^{[7]}$ but high in another ${ }^{[8]}$. Di (2ethylhexyl)phthalate (DEHP) is mainly used as a plasticizer of polyvinyl chloride (PVC) in the manufacture of a wide numbers of consumer products for building construction, automobiles, clothing, toys and medical devices ${ }^{[9-11]}$. DEHP was listed under the Harmless Drinking Water and Toxic Enforcement Act of 1986 (commonly known as Proposition 65, codified at Health and Safety Code Section 25249.5 et seq.) as known to the State to cause reproductive toxicity (developmental and male reproductive toxicity), effective October 24, 2003. This listing was based on formal identification of DEHP as causing developmental and male reproductive toxicity, by the National Institute for Occupational Safety and Health ${ }^{[12]}$. The scientific literatures with respect to Bpa and Dehp continues to grow, particularly in the area of endocrine distruptor but much work has not been done in the area of combine effect of Bpa and Dehp on body weight, liver and kidney. No acclaimed and organized center where these Bpa and Dehp hazards are characterized Enugu, Nigeria, thereby predisposing members of the populace to danger. Hence, the aim of this work is to evaluate the pathological effect of bisephenol a and $\operatorname{di}(2-$ etylhexyl)phthalate on weight, liver and liver function parameters of albino wistar rats

\section{Materials and Methods}

\subsection{Settings}

A total of 60 adult Wistar rats with average weight of $200-250 \mathrm{~g}$ were purchased from animal house, University of Nigeria, Enugu Campus.

\subsection{Ethical consideration}

The study was initiated after ethical approval from College of Medicine Ethical Committee (COMREC). With approval number :076/2018.

\subsection{Methods}

The animals were caged in a well-ventilated animal room with a 12:12 hr dark/light cycle and controlled temperature at $23 \pm 20^{\circ} \mathrm{C}$. 60 healthy albino rats of male sex aged 2-3 months and weighing between $200-250 \mathrm{~g}$ were divided into four groups (4) groups (labeled I-IV). Each group contained 15 Wistar rats. All the rats had access to standard commercially prepared pellet rat feed and pyogen free water. To investigate toxicity 60 were grouped into four and administered different concentration of BPA and DEHP within 48 hours for sign of cytotoxic effects such as dullness, depression, restlessness, diarrhea and death in extreme cases. From the result of the toxicity, the rat was administered with pelleted rat feed with considering the minimal dosage that the rat might be exposed to accidentally or naturally. Group II, III and IV were administered Bpa and Dehp daily mixed with pelleted rat feed orally in the morning and evening respectively. The group I received normal pelleted rat feed and water and served as control group, group II received with $5 \mathrm{mg} /$ feed daily of Bpa mixed with pelletd rat feed orally, group III received $0.5 \mathrm{mg} /$ feed daily of Dehp mixed with pelleted rat feed while group IV received oral mixture of $0.5 \mathrm{mg} /$ feed Bpa and $0.5 \mathrm{mg} / \mathrm{kg}$ Dehp + pelletd rat feed. The rats were fed orally regularly for 30 days and on completion of 30 days, the animals were weighed, sacrificed by cranial dislocation. The blood samples were obtained for kidney and liver function test. Standard procedure was used for liver and kidney function test ${ }^{[13-14]}$.

\subsection{Statistical analysis}

The obtained data were then subjected to statistical analysis using SPSS (version 25). The test groups' values were compared with the values of the control group using one-way analysis of variance (ANOVA) and Dunnett's test. Value less than 0.05 was considered statistical significant. 
Table 1: Liver Function Test of Test and Control Treated Rats

\begin{tabular}{|c|c|c|c|c|c|c|c|}
\hline LFT & GROUP I & GROUP II & PVALUE & GROUP III & PVALUE & E GROUP IV & PVALUE \\
\hline $\mathrm{TB}$ & $0.13 \pm 0.01$ & $0.20 \pm 0.00$ & $<0.01$ & $0.11 \pm 0.01$ & 0.99 & $0.100 \pm 0.00$ & 0.99 \\
\hline $\mathrm{CB}$ & $0.05 \pm 0.01$ & $0.13 \pm 0.01$ & $<0.01$ & $0.11 \pm 0.01$ & $<0.01$ & $0.0517 \pm 0.01$ & 0.81 \\
\hline AST & $88.42 \pm 6.19$ & $82.25 \pm 0.131$ & 1.00 & $61.58 \pm 0.19$ & 1.00 & $52.83 \pm 0.21$ & $<0.01$ \\
\hline ALT & $10.50 \pm 0.15$ & $20.58 \pm 0.19$ & $<0.01$ & $11.28 \pm 0.13$ & 0.99 & $10.33 \pm 0.14$ & 0.94 \\
\hline ALP & $21.67 \pm 0.14$ & $26.92 \pm 0.19$ & 0.008 & $.08 \pm 0.19$ & 0.98 & $15.08 \pm 0.19$ & 0.01 \\
\hline
\end{tabular}

Values are expressed as mean \pm standard deviation of mean

The sign $(*)$ denote significant at value less than or equal to 0.05

Keys: TB (total bilirubin), CB (Conjugated bilirubin), AST(Aspartate Transaminase ), ALT (Alanine transaminase),

ALP (Alkaline phosphatase)

\section{Results}

From table above, there is significant increase in $(\mathrm{P}<0.05)$ in the concentration of urea, sodium $(\mathrm{Na}+)$, creatinine and significant reduction $(\mathrm{p}<0.05)$ in urea, potassium $(\mathrm{K}+)$, bicarbonate $(\mathrm{HCO}-3)$ in group II in comparison with group 1 (control) but no significant difference $(\mathrm{p}>0.05)$ in the concentration of chloride (Cl-). In the group III, there was significant increase in $(p<0.05)$ in the concentration of urea, $\mathrm{Na}+$, and significant reduction $(\mathrm{p}<0.05)$ in the concentration of creatinine but no significant difference $(\mathrm{p}>0.05)$ in the concentration of $\mathrm{k}+$, bicarbonate and $\mathrm{Cl}-$. In the group IV, there was significant increase $(\mathrm{p}<0.05)$ in the concentration of urea, $\mathrm{Na}+$ and significant reduction $(\mathrm{P}<0.05)$ in the concentration of potassium $(\mathrm{K}+)$, creatinine and no significant difference $(\mathrm{p}<0.05)$ bicarbonate $(\mathrm{HCO}-3)$, chloride (Cl-)

Table 2: Renal Function Test of Treated Rats and Control

\begin{tabular}{lllllllll}
\hline PTERS & \multicolumn{1}{l}{ GROUP I } & \multicolumn{2}{l}{ GROUP II } & PVALUE & GROUP III & PVALUE GROUP IV PVALUE \\
\hline UREA & $32.33 \pm 0.45$ & $20.33 \pm 0.14$ & $<0.01$ & $46.92 \pm 0.29$ & $<0.01$ & $92.33 \pm 0.466$ & $<0.01$ \\
$\mathrm{NA}+$ & $117.08 \pm 0.34$ & $142.08 \pm 0.57$ & $<0.01$ & $123.05 \pm 0.67$ & $<0.01$ & $138.83 \pm 0.345$ & $<0.01$ \\
$\mathrm{~K}+$ & $16.100 \pm 0.21$ & $8.86 \pm 0.29$ & $<0.01$ & $16.20 \pm 0.05$ & 0.21 & $8.92 \pm 0.09$ & $<0.01$ \\
$\mathrm{HCO}_{3}^{-}$ & $20.42 \pm 0.15$ & $10.42 \pm 0.19$ & $<0.01$ & $19.08 \pm 0.149$ & 1.00 & $20.00 \pm 0.30$ & 1.00 \\
$\mathrm{CL}^{-}$ & $110.75 \pm 0.25$ & $107.25 \pm 0.35$ & 1.00 & $92.92 \pm 0.379$ & 1.00 & $108.75 \pm 0.24$ & 0.07 \\
$\mathrm{CR}$ & $0.50 \pm 0.02$ & $0.58 \pm 0.01$ & $<0.01$ & $0.42 \pm 0.01$ & $<0.01$ & $0.28 \pm 0.03$ & $<0.01$ \\
\hline
\end{tabular}

Values are expressed as mean \pm standard deviation of mean

The sign $(*)$ denote significant at value less than or equal to 0.05

Keys: Sodium (Na+), Potassium $(\mathrm{K}+)$, Chloride $\left(\mathrm{CL}^{-}\right)$, Bicarbonate $\left(\mathrm{HCO}_{3}^{-}\right)$, Creatinine $(\mathrm{CR})$

This present work shows significant increase in $(\mathrm{P}<0.05)$ in the concentration of urea, sodium $(\mathrm{Na}+)$, creatinine and significant reduction $(\mathrm{p}<0.05)$ in urea, potassium $(\mathrm{K}+)$, bicarbonate $(\mathrm{HCO}-3)$ in group II when compare with the control (group I) but no significant difference $(\mathrm{p}>0.05)$ in the concentration of chloride (Cl-). In the group III, there was significant increase in $(\mathrm{p}<0.05)$ in the concentration of urea, $\mathrm{Na}+$, and significant reduction $(\mathrm{p}<0.05)$ in the concentration of creatinine but no significant difference $(p>0.05)$ in the concentration of $\mathrm{k}+$, bicarbonate and $\mathrm{Cl}-$. In the group IV, there was significant increase $(\mathrm{p}<0.05)$ in the concentration of urea, $\mathrm{Na}+$ and significant reduction $(\mathrm{P}<0.05)$ in the concentration of potassium $(\mathrm{K}+)$, creatinine and no significant difference $(\mathrm{p}<0.05)$ bicarbonate $(\mathrm{HCO}-3)$, chloride (Cl-) 


\section{Discussion}

The significant increase in the conjugated bilirubin and total bilirubin could have resulted from biliary obstruction or parenchymal liver disease. The increase in the alanine transaminase could be due to autoimmune liver disease because alanine transaminase is present normally in the liver tissues. The high increase could have resulted the body immune system trying to fight the foreign substance Bpa. The significant increase in the alanine transaminase of the group treated with bisephenol A corresponded with the previous work by Wei Xia et al ${ }^{[15-18]}$. The significant increase in the conjugated bilirubin of the group exposed to $\operatorname{Di}(2-$ ethylhexyl)phathalate may have resulted from biliary obstruction by the substance Dehp. The significant increase in alanine transaminase and alkaline phosphatase could have been due to the liver trying to detoxify the foreign substances in the system. The increased in creatinine concentration in Bpa treated rats correlated with the previous work conducted by Anongporn et al. ${ }^{[19]}$ The increase in creatinine and sodium of the group exposed to Bpa could have been due to the inhibitory effect on the glomeruli filtrate function of the kidney ${ }^{[19]}$. Creatinine clearance is part of the measure in ensuring the glomeruli filtrate in kidney is functioning properly, if the serum creatinine is increased that means the glomeruli filtrate is not functioning properly as in the case of the groups administered with Bpa. The significant increase in the urea and sodium of the albino rats due to the exposure to Dehp could have resulted from inhibitory effect of the Dehp on the selective reabsorption and glomeruli filtration functioning of the kidney. This increase could be attributed to impairment of the kidney functioning ${ }^{[20]}$. The significant difference in the group treated with Dehp also similar to previous work done by Raymond et al and Miura et al ${ }^{[21-23]}$. This is to show that combining effect of Bpaand Dehp can impede the functioning of the liver and kidney. significant reduction in the sizes of the rat may have resulted from Bpa and Dehp preventing growth or development of the rats. It could also be due to the inhibitory properties of Dehp and Bpa on growth hormones ${ }^{[24-25]}$.

\section{Conclusion}

In conclusion the present work reveals that Bpa and Dehp can severely affect the proper functioning of the liver and kidney both in combine administration and in separate administration. Bpa and Dehp can lead to severe emaciation of the rat.

\section{Recommendations}

We recommend further research possibly on human experimentation.

\section{Reference}

1 Jaakkola JJ, Parise H, Kislitsin V, Lebedeva NI, Spengler JD. Asthma, wheezing, and allergies in Russian schoolchildren in relation to new surface materials in the home. Am J Public Health 2004; 94(4): 560-562 [PMID: 15054004 PMCID: PMC1448297]

2 Tuomainen A, Stark H, Seuri M, Hirvonen MR, Linnainmaa M, Sieppi A, Tukiainen H. Experimental PVC material challenge in subjects with occupational PVC exposure. Environ Health Perspect 2006; 114(9): 14091413 [PMID: 16966097 PMCID: PMC1570076 DOI: 10.1289/ehp.8965]

3 Bornehag CG, Nanberg E. Phthalate exposure and asthma in children. Int $\boldsymbol{J}$ Androl 2010; 33(2): 333-345 [PMID: 20059582 DOI: 10.1111/j.1365-2605.2009.01023.x]

4 Jaakkola JJ, Verkasalo PK, Jaakkola N. Plastic wall materials in the home and respiratory health in young children. Am J Public Health 2000; 90(5): 797-799 [PMID: 10800434 PMCID: PMC1446240]

5 Bornehag CG, Sundell J, Weschler CJ, Sigsgaard T, Lundgren B, Hasselgren M, Hagerhed-Engman L. The association between asthma and allergic symptoms in children and phthalates in house dust: a nested case-control study. Environ Health Perspect 2004; 112(14): 1393-1397 [PMID: 15471731 PMCID: PMC1247566 DOI: 10.1289/ehp.7187]

6 Jaakkola JJ, Knight TL. The role of exposure to phthalates from polyvinyl chloride products in the development of asthma and allergies: a systematic review and meta-analysis. Environ 
Health Perspect 2008; 116(7): 845-853 [PMID: 18629304 PMCID: PMC2453150 DOI: 10.1289/ehp.10846]

7 Shin BS, Kim C.H, Jun Y.S, Kim D.H, Lee B.M, Yoon C.H, Park E.H, Lee K.C, Han S.Y, Park KL, Kim H.S, Yoo S.DPhysiologically based pharmacokinetics of bisphenol A. $\boldsymbol{J}$

Toxicol Environ Health A. 2004;67:19711985.

8 Nunez AA, Kannan K, Giesy JP, Fang J, Clemens LG. Effects of bisphenol A on energy balance and accumulation in brown adipose tissue in rats. Chemosphere 2001; 42(8): 917 922 [PMID: 11272914]

9 Scenihr . Preliminary report on the safety of medical devices containing DEHP-plasticized or other plasticizers on neonates and other groups possibly at risk82-44.rats. Toxicology. 2007;213:13-24.

10 Howdeshell KL, Hotchkiss AK, Thayer KA, Vandenbergh JG, vom Saal FS. Exposure to bisphenol A advances puberty. Nature 1999; 401(6755): 763-764 DOI: $10.1038 / 44517$

11 Bosnir J, Puntaric D, Skes I, Klaric M, Simic S, Zoric I. Migration of phthalates from plastic products to model solutions. Coll Antropol 2003; 27 Suppl 1: 23-30 [PMID: 12955888]

12 NIOSH. Manual of analytical method (NMAM). Di(2-ethylhexyl)phthalate Method 5020. DHHS (NIOSH). Schelect PC O' Connol PC editor. Cincinnati oh. National Institute for occupational safety and health.2003; 2003154

13 Cheesbrough ,M. District Laboratory Practice in the Tropical countries part 2.(2nd ed.) Cambridge University Press. 2006;Pp 209-334.

14 Roche Diagnostics, Procedural insert: 2000;917

15 Wei Xia., Ying Jiang., Yuanyuan Li, Yanjian Wan, Juan Liu, Yue Ma, Zhenxing Mao, Huailong Chang, Shehata AS, El-Rehim Mohamed ZA, El-Haleem MRA, Samak MA Effects of Exposure to Plasticizers Di-(2Ethylhexyl)Phthalateand Trioctyltrimellitate on the Histological Structure of Adult Male Albino Rats' Liver. J Clin Toxicol. 2013; 3: 169. doi:10.4172/2161-0495.1000169.
16 Ozra Rahimi, Farah Farokhi, Seyed Mahdi Khojariah . The effect of Bisephenol A on live tissue structure and liver enzymes. Qom University of Medical Science Journal.2016;9 (12) : $1-7$

17 Jassim M.A., Alkalby.. Effect of Bisephenol A on Thyroid, Liver and Testiscular functions in Adult male Rats.Bas. J. Vet.2007;15 (1):187206

18 Kobroob A, Peerapanyasut W, Chattipakorn N, Wongmekiat $O$. Damaging Effects of Bisphenol A on the Kidney and the Protection by Melatonin: Emerging Evidences from In Vivo and In Vitro Studies. Oxid Med Cell Longev 2018; 2018: 3082438 DOI: $10.1155 / 2018 / 3082438$

19 Simon P, Ramee MP, Boulahrouz R, Stanescu C, Charasse C, Ang KS, Leonetti F, Cam G, Laruelle E, Autuly V, Rioux N. Epidemiologic data of primary glomerular diseases in western France. Kidney Int 2004; 66(3): 905-908 DOI: 10.1111/j.1523-1755.2004.00834.X

20 Mourad, I.M., Khadrawy, Y.A. The sensetivity of Liver, Kidney and testis of rats to oxidative stress induced by different doses of Bisphenol A. International Journal of Life Science and Pharma Reviews 2012; 2, 19-28.

21 David RM, Moore MR, Finney DC, Guest D. Chronic toxicity of di(2-ethylhexyl)phthalate in rats. Toxicol Sci 2000; 55(2): 433-443

22 Miura Y, Naito M, Ablake M, Terayama H, Yi SQ, Qu N, Cheng LX, Suna S, Jitsunari F, Itoh M. Short-term effects of di-(2-ethylhexyl) phthalate on testes, liver, kidneys and pancreas in mice. Asian J Androl 2007; 9(2): 199-205 DOI: 10.1111/j.1745-7262.2007.00220.x

23 Rahimi, O., Farokhi, F., Khojasteh M. B., Ozi, S.A. The effect of Bisehephenol A on serum parameters and morphology of kidney's tiisues. Biology forum-An int. J. 2015;7(2):79-90.

24 Wittassek, M., Angerer, J . Phthalates: metabolism and exposure. Int. J. Androl. 2008; 31:131- 138 .

25 Rehab M. Hussein and Jehane I. Eid. Pathological mechanisms of liver injury caused by oral administration of bisphenol A. Life Sci J.2013;10 (1):663-673. 